\title{
Peertechz
}

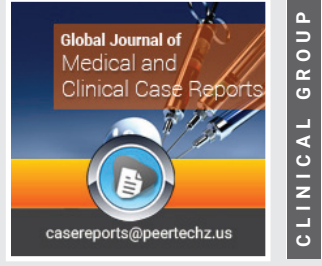

\section{A comparative study to analyze the effect of planter fascia stretch and heel pad with moist heat in the patients of planterfascitis}

Received: 27 July, 2021

Accepted: 10 August, 2021

Published: 12 August, 2021

*Corresponding author: Umair Arif, Lecturer, Department of Management Studies, the University of Faisalabad, Pakistan, Tel: +923317104313; E-mail: umairrana1765@gmail.com, umair.arif@tuf.edu.pk Keywords: Planterfascitis; Planter fascia stretch; Heel pad with moist heat

https://www.peertechzpublications.com

\section{Check for updates}

\section{Komal Razzaq ${ }^{1}$, Umair Arif ${ }^{2 \star}$, Iqra Tahir ${ }^{3}$, Touseef-ur- Rehman $^{3}$, Asima Liaqat ${ }^{3}$, Kaiynat Shafique ${ }^{3}$ and Hafiz Muhammad Almas Sabir ${ }^{3}$}

'Department of Physiotherapy, University of Faisalabad, Pakistan

${ }^{2}$ Department of Management Studies, University of Faisalabad, Pakistan

${ }^{3}$ Visiting Lecturer, Govt College University of Faisalabad, Pakistan

\section{Abstract}

Background: This study investigated the effect of planter fascia stretch and heel pad with moist heat in the patients of planterfascitis among subjects aged 20-40. Planter fascia is a thickened fibrous sheet of connective tissue which begins from medial tubercle on undersurface of calcaneus and fans out joining to the metatarsophalangeal joints plates to form longitudinal foot arch. Manual active stretching or passive stretching of planter fascia and Achilles tendon are effective treatment option for patient with planter fasciitis. Aims and objectives: objectives of this study were to see the effect of planter fascia stretch and heel pad with moist heat in the patients of planterfascitis.

Material and methodology: This study was quasi experimental study. It took samples by convenient method from 80 subjects among Faisalabad private hospitals community. The study was completed in the duration of 3 months. Data was conducted through convenient sampling from Faisalabad private hospitals. This study explored the effect of planter fascia stretch and heel pad with moist heat on subjects aging 20-40 years old. Subjects were allocated to group $A$ ( $n=40$ ) and group $B$ ( $n=40$ ). Group A received treatment as planter fascia stretch and group B received treatment as heel pad with moist heat. Follow up were taken after 4 weeks in 3 month duration study.

Results: Statistical Analysis Data were analyzed using SPSS version 23.0. Intragroup comparison of differences between pre and post intervention scores of FFI and FADI was analyzed using independent T Test. The results were considered statistically significant if $p$ values were less than 0.05 ). No statistically significant difference was observed in pre intervention score between the groups on FADI $(p=0.211)$ and FFI $(p=0.365)$, but, statistically significant difference was observed between all the groups on post intervention score with respect to FADI $(p=0.000)$ and FFI $(p=.001)$ as analyzed by independent $t$ test.

Conclusion: After applying the entire treatments and measuring pre and post value it conducted that planter fascia stretch has more significant effect on planterfascitis than heel pad with moist heat.

\section{Introduction}

Planter fascia is a thickened fibrous sheet of connective tissue which begins from medial tubercle on undersurface of calcaneus and fans out joining to the metatarsophalangeal joints plates to form longitudinal foot arch. Planter fasciitis is a degenerative syndrome of planter fascia due to repeated trauma as its origin on the calcaneus. Planter fasciitis is very significant cause of pain of heel on slightly inferior side [1]. Discomfort and pain related with condition can have considerable effect on physical mobility. Etiology of planter fasciitis is multifactorial in nature. Increase in weight, anatomical changes improper foot wear, bad biomechanics, work related issues and over activities are major contributing factors in developing the condition of planter fasciitis $[2,3]$. 
Sometimes it becomes severe and take month or even year to resolve and become challenging for clinicians .Other names for planter fascitis includes calcaneodynia, sub calcaneal pain, runners heel, heel spur syndrome and painful heel syndrome. Decreased ankle dorsiflexion, weight bearing for long period, pes planes and sudden weight gain are the major risk factors for planter fasciitis. Signs and Symptoms are localized tenderness of calcaneus bone at anteromedial aspect, stiffness of Achilles tendon, pain increased by passive dorsiflexion of toes after standing on tip of toes [2]. Significant pain after performing heavy activities or after weight bearing exercise. The exact presentation of planter fascitis is pain on the sole foot at inferior border of heel. Patient feels severe pain after taken few steps in morning [4].

Most options for treatment are available which show different level of efficiency. Some conservatives options for treatment like rest, avoiding aggressive or heavy activity, strengthening and stretching excercises,night splinting and orthotics.Other options to treat planter fascitis are anti inflammatory agents, electrotherapy (Ultrasonic shock wave therapy), steroidal injection and surgery.Time to resolve this issue varies from almost 6 to 18 months. Sometimes may be longer which may become challenge for both patient and clinician.Many experts think identification, diagnosis and treatment in early stage of disease brings better recovery in comperatively short period of time [5,6].

Splinting and walking casts help the patient of planter fascitis to keep his foot in neutral position overnight.It reduces the pressure on heel at heel strike.Silicon insole is a noninvasive treatment option which add comfort and provide soothing effect to heal as it absorbs about $50 \%$ of shock during walking. Some studies suggests that silicon insole provide good relief to patient with planter fascitis that the custom made orthotics and stretching exercises do alone and it is one of most effective treatment option for increasing functional status and decreasing pain in patient with planter fascitis pain $[7,8]$.

Manual active stretching or passive stretching of planter fascia and Achilles tendon are effective treatment option for patient with planter fascitis. There are many studies have been tested the efficiency of planter fascia stretch and Achilles tendon stretch with positive result. Some studies also evaluated the effectiveness of combined treatment including ultrasound or radial shock wave therapy and stretching exercises the result of the same studies suggested that combined treatment of stretching of gastrocnemius and ultrasound and planter fascia being are as effective as radial shock wave therapy and stretching of planter fascia and gastrocnemius.Some studies showed the result for combined treatment of calcaneal taping and planter fascia stretch. [9].

Stretching of calf muscle is also very effective in patient of planter fascia according to same studies. Only some studies that suggest the superior of calf stretch over planter fascia stretch or planter fascia stretch over calf stretch. Some studies also compared the superiority of planter stretch over stretch of tendon Achilles and the result revealed the stretch of planter fascia is relatively more effective than tendon Achilles stretch in patient of planter fascia. Combination of both stretch (planter fascia stretch and calf stretch) are very effective in resolving the issue, restoring the normal range of motion and decreasing the pressure from stiff and tight planter fascia.But there is no study has identified the independent efficiency of these exercises $[10,11]$.

Some studies show that non-steroidal anti-inflammatory drugs in decreasing pain and reducing the inflammation of planter fascia, but the efficiency of these drugs in patient with chronic issue still remain obscure [12]. Some researches show the positive result with moist heat while treating patient with planter fascia but the effectiveness of moist heat in isolation remains uncertain. Moist heat shows better result when used in combination with other modalities like heel pad $[13,14]$.

To our knowledge ,there will be no literature of study that has compared and assess independent efficiency of two common used treatment modalities like heel pad with hot fomentation and stretching exercises of planter fascia. So, the objective of recent study is to evaluate the response of planter fascitis patient to different treatment options when given separately that may support to establish a conclusive treatment strategy for managing patient with planter fascitis [3,14]

\section{Material and methodology}

This study was quasi experimental study. Sample size was 80 that had been collected by convenient sampling from private hospitals of Faisalabad. The study was completed in the duration of 6 months. It is used to see the effect of planter fascia stretch and heel pad with moist heat in the patients of planter fasciitis. This study explored the effect of planter fascia stretch and heel pad with moist heat on subjects aging 20-40 years old. Subjects were allocated to group $A(n=40)$ and group $B(n=40)$ by convenient sampling. Group A received treatment as planter fascia stretch and group B received treatment as heel pad with moist heat.

\section{Inclusion criteria}

- Both males and females of age 20-40.

- Moderate to severe intensity with minimum duration of 4 weeks.

\section{Exclusion criteria}

\section{- History of steroid injections}

\section{- History of surgery in affected lower limb}

- Any other pathology that can cause pain in heal patients having any psychological dysfunction.

It was a quasi-experimental study in which 80 members of both genders are equally divided into two groups of group $\mathrm{A}$ and group B with 40, 40 members in which group A received treatment as heel pad with moist heat while group $B$ received treatment as planter fascia stretch. A treatment given to both groups for 4 days per week and pre and post values had been noted. Both treatments were given under supervision. 


\section{Statistical analysis}

Statistical Analysis Data were analyzed using SPSS version 23.0. Intragroup comparison of differences between pre and post intervention scores of FFI and FADI was analyzed using independent $\mathrm{T}$ Test. The results were considered statistically significant if $\mathrm{p}$ values were less than 0.05 .

\section{Results}

Total 80 patients were included in our study. 40 were randomly allocated to group A and 40 were allocated to group B. Out of 80 patients $34(42 \%)$ were male and $46(58 \%)$ were female (Figure 1). Out of 80 patients 11 were lie in age group of 20-25, 17 were lie in age group of $26-30,23$ were lie in age group of $31-35$ and 29 were lies in age group of 36-40. Average age was $32.61 \pm 3.94$ (Figure 2). Out 80 patients 57 were overweight and 23 were not overweight. Average BMI was 27.32 \pm 4.82 (Figure 3). Significant difference was founded on FADI score on both pairs with p-value 0.000 (Table 1). Significant difference was founded on FFI score on both pairs with p-value 0.000 (Table 2). No statistically significant difference was observed in pre intervention score between the groups on FADI $(p=0.211)$ and FFI ( $p=0.365)$, but, statistically significant difference was observed between all the groups on post intervention score with respect to FADI $(\mathrm{p}=0.000)$ and FFI $(\mathrm{p}=.001)$ as analyzed by independent $t$ test (Tables 3,4).

\section{Gender distribution}

male female

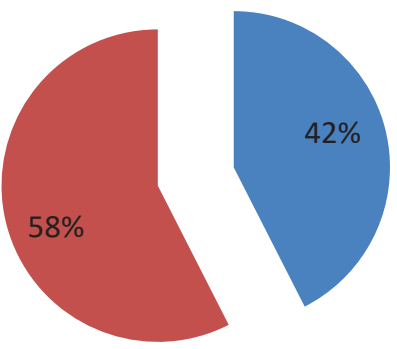

Figure 1: Gender distribution

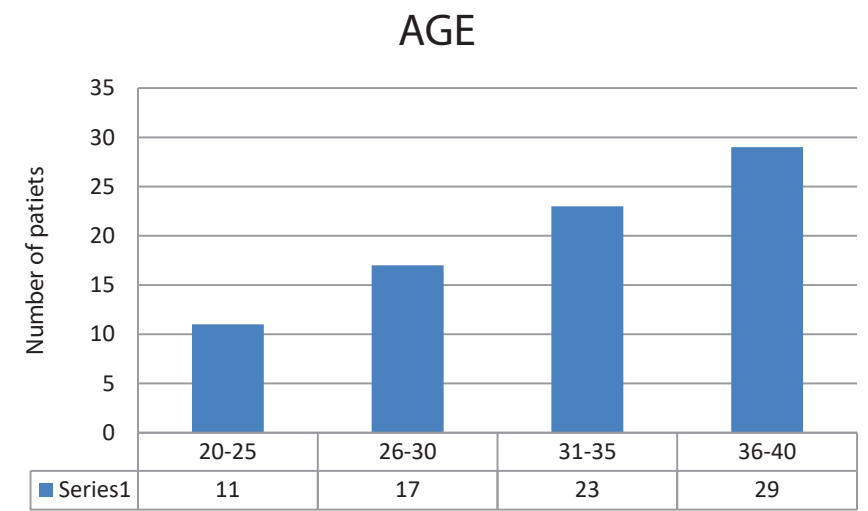

Figure 2: Age distribution
BMI

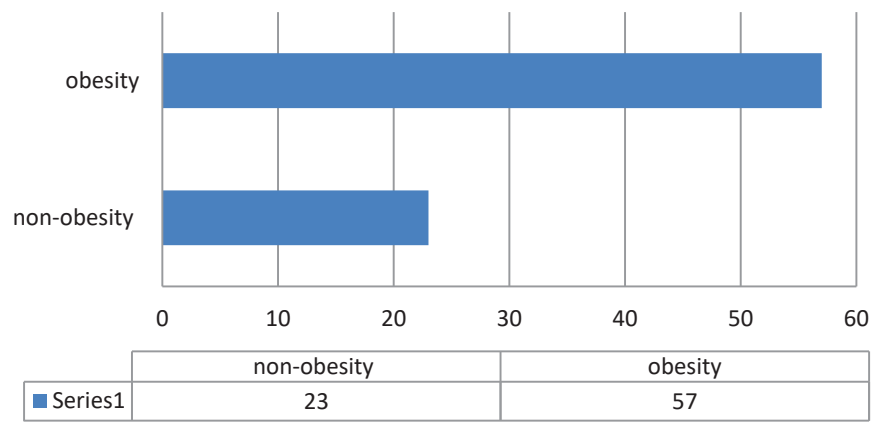

Figure 3: BMI Categories.

Table 1: Fadi Score Comparison

\begin{tabular}{|c|c|c|c|}
\hline Group & Mean pre intervention score & Mean post intervention score & p-value \\
\hline Paire-1 & 62.38 & 81.3 & .000 \\
\hline Paire-2 & 66.20 & 90.63 & .000 \\
\hline
\end{tabular}

Table 2: FFI score comparison

\begin{tabular}{|l|l|l|l} 
Group & Mean pre intervention score & Mean post intervention score & p-value
\end{tabular}

\begin{tabular}{|l|l|l|l|}
\hline Paire-1 & 67.24 & 35.98 & .001 \\
\hline Paire-2 & 69.89 & 13.11 & .001 \\
\hline
\end{tabular}

Table 3: Independent $t$ test on pre and post intervention FADI score of both groups.

\begin{tabular}{|c|c|}
\hline Independent T test & p-value \\
\hline Pre Intervention & 0.211 \\
\hline Post Intervention & 0.000 \\
\hline
\end{tabular}

Table 4: Independent $t$ test on pre and post intervention FFI score of both groups.

\begin{tabular}{|c|c|}
\hline Independent T test & P-value \\
\hline Pre Intervention & 0.365 \\
\hline Post Intervention & 0.001 \\
\hline
\end{tabular}

\section{Discussion}

Plantar fasciitis is a debilitating condition that causes pain on the inferior aspect of the foot, particularly when taking the first few steps in the morning. Most options for treatment are available which show different level of efficiency. Some conservativesoptions for treatment like rest, avoiding aggressive or heavy activity, strengthening and stretching excercises, night splinting and orthotics [15]. To our knowledge, there will be no literature of study that has compared and assess independent efficiency of two common used treatment modalities like heel pad with hot fomentation and stretching exercises of planter fascia [6]. So, the objective of recent study is to evaluate the response of planter fascitis patient to different treatment options when given separately that may support to establish a conclusive treatment strategy for managing patient with planter fascitis. In our study total 80 patients were included and randomly allocated to group A and B. Out of 80 patients $34(42 \%)$ were male and $46(58 \%)$ were female. In the present study, we have observed the predominance of female 
patients over the male patients. This is in line with the study of Davis, et al. 74 female patients and 31 male patients with plantar fasciitis were included, and in another study by Yucel, et al. heel pain was found to be more common in the female population (76.6 percent in females vs. 23.3 percent in males. This disparity between male and female ratios in our sample may be attributed to factors such as long periods of standing, more frequent use of overweight or high heel boots, and the habit of barefoot walking among women.Out of 80 patients in our study, 11 were lie in age group of $20-25,17$ were lie in age group of $26-30,23$ were lie in age group of $31-35$ and 29 were lies in age group of $36-40$. This shows that the prevalence of planter fasciitis increases with the age. These results are in accordance with the study of Matheson, et al. They discovered that younger athletes had a lower incidence of plantar fasciitis $(2.5 \%)$ than older athletes $(6.6 \%)$ in a retrospective study of 1407 patients from an outpatient sports medicine clinic.

Results of the present study depict that the plantar fascia stretching group showed more reduction in pain and improvement in activities as compared to the silicone heel pad plus hot fomentation group as observed from mean difference. Significant difference was founded on FADI score on both pairs with p-value 0.000 . Significant difference was founded on FFI score on both pairs with p-value 0.000 . No statistically significant difference was observed in pre intervention score between the groups on FADI $(p=0.211)$ and FFI $(p=0.365)$, but, statistically significant difference was observed between all the groups on post intervention score with respect to FADI $(p=0.000)$ and FFI $(p=.001)$. Pfefer, et al. [16] compared three prefabricated shoe inserts (a rubber heel cup, a felt insert, and a silicone heel pad) with Achilles tendon and plantar fascia stretching against stretching alone on 236 patients in a randomised controlled study. Just 190 patients completed the 8-week follow-up, but the silicone insert group had a higher response rate than the stretching-only group $(\mathrm{p}=0.019)$. Although the silicone insert group improved better on FFI than the stretching alone group, there was no statistically significant difference $(p=0.54)$ [17]. Another research by Yucel, et al. found that after using full-length insoles, the condition of $80 \%$ of patients improved, with a statistically significant difference in mean pain ratings at $\mathrm{p}<0.05$.The difference in findings may be due to the short-term follow-up and usage of silicone heel inserts in combination with other treatment modalities in these trials. Heat and moist heat were found to be helpful in reducing pain by Petrofsky, et al. during their research. However, their research had one limitation: heat was used in conjunction with or without Advil to treat plantar fasciitis [17].

Davis, et al. published a retrospective review, conducted on 105 patients, 89 percent of patients were shown to improve signifcantly with non-operative treatment which included rest, NSAIDs, Achilles tendon and plantar fascia stretching exercises, and heel cushions [18]. Stretching exercises, on the other hand, were found to be the most effective therapy for plantar fasciitis in their research. For a better result, various writers have recommended the use of stretching exercises in the treatment of plantar fasciitis. The effect of plantar fascia and calf stretching exercises was seen in 101 patients suffering from chronic plantar fasciitis in phase one of a clinical trial for 8 weeks of treatment, according to Digiovanni, et al. [19]. The treatment plan also included prefabricated soft insoles and a 3-week course of celecoxib, in addition to the stretching exercises. After 8 weeks, patients in the plantar fascia stretching community showed significant improvement on the FFI pain score in terms of worst pain; $p=0.02$ and first steps in the morning; $p=0.006$, but no significant improvement was shown when all of the FFI components were compared. After 8 weeks of care, patients in the calf stretch group were advised to perform plantar fascia stretching exercises. At 2 years of follow-up in phase two of the clinical trial both groups progressed significantly in terms of pain and visual analogue scale scores from baseline on FFI score (po.0001). As a result, these findings indicate that plantar fascia stretching exercises offer greater symptom relief in cases of plantar fasciitis [20, 21].

\section{Conclusion}

After applying the entire treatments and measuring pre and post value it is concluded that Planter fascia stretching exercises resulted in most significant improvement in both scores (FFI and FADI), followed by treatment with heel pad and moist heat.

\section{References}

1. Shim DW, Sung SY, Chung WY, Kang KY, Park SJ, et al. (2021) Superior pedal function recovery of newly designed three spike insole over total contact insole in refractory plantar fasciitis: A randomized, double-blinded, noninferiority study. PloS One 16: e0255064. Link: https://bit.ly/2VKrrnW

2. Trojian T, Tucker AK (2019) Plantar fasciitis. Am Fam Physician 99: 744-750. Link: https://bit.ly/37wK6GH

3. Vahdatpour B, Mokhtarian A, Raeissadat SA, Dehghan F, Nasr N, et al. (2018) Enhancement of the effectiveness of extracorporeal shock wave therapy with topical corticosteroid in treatment of chronic plantar fasciitis: a randomized control clinical trial. Adv Biomed Res 7: 62.

4. Liu CL, Zhou JP, Sun PT, Chen BZ, Zhang J, et al. (2020) Influence of different knee and ankle ranges of motion on the elasticity of triceps surae muscles, Achilles tendon, and plantar fascia. Scientific Reports 10: 1-10. Link: https://go.nature.com/37wsESy

5. Ermutlu C, Aksakal M, Gümüştaş A, Özkaya G, Kovalak E, et al. (2018) Thickness of plantar fascia is not predictive of functional outcome in plantar fasciitis treatment. Acta Orthop Traumatol Turc 52: 442-446. Link: https://bit.ly/3s6fDZk

6. Gupta R, Malhotra A, Masih GD, Khanna T, Kaur H, et al. (2020) Comparing the role of different treatment modalities for plantar fasciitis: a double blind randomized controlled trial. Indian J Orthop 54: 31-37. Link: https://bit.ly/3ylWvDi

7. Menon NA, Jain J (2018) Plantar fasciitis: A review. Indian Journal of Pain 32 : 24. Link: https://bit.ly/3s6lEp5

8. Yick KL, Tse CY (2021) The use of textiles and materials for orthopedic footwear insoles. Handbook of Footwear Design and Manufacture: Elsevier 361-88

9. Luffy L, Grosel J, Thomas R, So E (2018) Plantar fasciitis: a review of treatments. Journal of the American Academy of PAs. 31: 20-24. Link: https://bit.ly/3xCtqZ0 
10. Lee JH, Park JH, Jang WY (2019) The effects of hip strengthening exercises in a patient with plantar fasciitis: A case report. Medicine 98: e16258. Link: https://bit.ly/3fUgcAz

11. Chen Z, Li J, Song W, Lu Y, Cao B (2020) Smart Wireless Charging Heating Insoles: Improving Body Thermal Comfort of Young Males in an Extremely Cold Environment. Clothing and Textiles Research Journal. Link: https://bit.ly/3jJGwyH

12. Fry DA (2019) Is Botulinum Toxin Injection Effective in Reducing Pain in Patients Diagnosed with Plantar Fasciitis?. Link: https://bit.ly/3xxthWA

13. Sud A, Ranjan R (2018) Textbook of Orthopaedics, -E-Book: Elsevier Health Sciences.

14. Mev V, Nama D, Sharma V, Agarwal P (2015) Heel pain: A systematic review with homoeopathic management.

15. LaLonde M (2020) At-home exercises for 4 common musculoskeletal complaints. J Fam Pract 69: 484-492. Link: https://bit.ly/3s6L8CF

16. Yadav L, Sarkar B, Kumar P, Kumar A (2019) Effect of Calcaneal Taping on Pain, Pressure Pain Threshold \& Function in Subjects with Chronic Plantar Fasciitis: A Randomized Clinical Trial 9: 124-131. Link: https://bit.ly/3yDrVe5
17. Petrofsky J, Laymon M, Lee H (2020) Local heating of trigger points reduces neck and plantar fascia pain. J Back Musculoskelet Rehabil 33: 21-28. Link: https://bit.ly/3s99qft

18. Divyarasi N, Desarda R (2021) Plantar Fasciitis and Its Homoeopathic Management. Journal of Medical and Pharmaceutical Innovation 8: 15-20.

19. Chen TLW, Wong DWC, Peng Y, Zhang M (2020) Prediction on the planta fascia strain offload upon Fascia taping and Low-Dye taping during running Journal of Orthopaedic Translation 20: 113-121. Link: https://bit.ly/3xE7HzQ

20. Ostermann S, Olesen JL, Holden S, Riel H (2020) Stretching and relaxing the plantar fascia may change plantar fascia thickness but not pressure pain thresholds: a cross-sectional study of patients with plantar fasciopathy. BMC Musculoskeletal Disorders 21: 1-8. Link: https://bit.ly/3s6fwNo

21. Welte L, Kelly LA, Kessler SE, Lieberman DE, D'Andrea SE, et al. (2021) The extensibility of the plantar fascia influences the windlass mechanism during human running. Proceedings of the Royal Society B 288: 20202095. Link: https://bit.ly/3sfiAXF

\section{Discover a bigger Impact and Visibility of your article publication with}

\section{Peertechz Publications}

\section{Highlights}

* Signatory publisher of ORCID

* Signatory Publisher of DORA (San Francisco Declaration on Research Assessment)

- Articles archived in worlds' renowned service providers such as Portico, CNKI, AGRIS, TDNet, Base (Bielefeld University Library), CrossRef, Scilit, J-Gate etc.

* Journals indexed in ICMJE, SHERPA/ROMEO, Google Scholar etc.

* OAI-PMH (Open Archives Initiative Protocol for Metadata Harvesting)

* Dedicated Editorial Board for every journal

* Accurate and rapid peer-review process

* Increased citations of published articles through promotions

* Reduced timeline for article publication

Submit your articles and experience a new surge in publication services (https://www.peertechz.com/submission).

Peertechz journals wishes everlasting success in your every endeavours.

Copyright: @ 2021 Razzaq K, et al. This is an open-access article distributed under the terms of the Creative Commons Attribution License, which permits unrestricted use distribution, and reproduction in any medium, provided the original author and source are credited.

Citation: Razzaq K, Arif U, Tahir I, Rehman TU, Liaqat A, et al. (2021) A comparative study to analyze the effect of planter fascia stretch and heel pad with moist heat in the patients of planterfascitis. Glob J Medical Clin Case Rep 8(2): 087-091. DOI: https://dx.doi.org/10.17352/2455-5282.000136 